Article

\title{
System of Variational Inclusions and Fixed Points of Pseudocontractive Mappings in Banach Spaces
}

\author{
Lu-Chuan Ceng ${ }^{1}$, Mihai Postolache ${ }^{2,3,4, * \mathbb{D}}$, Xiaolong Qin ${ }^{5}$ and Yonghong Yao ${ }^{6}$ \\ 1 Department of Mathematics, Shanghai Normal University, Shanghai 200234, China; zenglc@hotmail.com \\ 2 Center for General Education, China Medical University, Taichung 40402, Taiwan \\ 3 Romanian Academy, Gh. Mihoc-C. Iacob Institute of Mathematical Statistics and Applied Mathematics, \\ Bucharest 050711, Romania \\ 4 University "Politehnica" of Bucharest, Department of Mathematics and Informatics, Bucharest 060042, Romania \\ 5 Institute of Fundamental and Frontier Sciences, University of Electronic Science and Technology of China, \\ Chengdu 611731, China; qxlxajh@163.com \\ 6 School of Mathematical Sciences, Tianjin Polytechnic University, Tianjin 300387, China; \\ yaoyonghong@aliyun.com \\ * Correspondence: emscolar@yahoo.com
}

Received: 9 December 2018; Accepted: 18 December 2018; Published: 20 December 2018

\begin{abstract}
The purpose of this paper is to solve the general system of variational inclusions (GSVI) with hierarchical variational inequality (HVI) constraint, for an infinite family of continuous pseudocontractive mappings in Banach spaces. By utilizing the equivalence between the GSVI and the fixed point problem, we construct an implicit multiple-viscosity approximation method for solving the GSVI. Under very mild conditions, we prove the strong convergence of the proposed method to a solution of the GSVI with the HVI constraint, for infinitely many pseudocontractions.
\end{abstract}

Keywords: implicit multiple viscosity approximation method; system of variational inclusions; pseudocontractive mapping; nonexpansive mapping

MSC: 47H05; 47H10; 47J25

\section{Introduction}

Let $C$ be a nonempty closed convex subset of a real Hilbert space $H$ equipped with inner product $\langle\cdot, \cdot\rangle$ and norm $\|\cdot\|$. Let $S: C \rightarrow C$ be nonexpansive, with its fixed point set $F(S) \neq \varnothing$. Let $A, B: C \rightarrow H$ be $\alpha$-inverse-strongly monotone and $\beta$-inverse-strongly monotone, respectively. In 2008, Ceng et al. [1] introduced and considered the following general system of variational inequality problems of finding $\left(x^{*}, y^{*}\right) \in C \times C$, such that

$$
\left\{\begin{array}{l}
\left\langle\rho A y^{*}+x^{*}-y^{*}, x-x^{*}\right\rangle \geq 0, \forall x \in C, \\
\left\langle\eta B x^{*}+y^{*}-x^{*}, x-y^{*}\right\rangle \geq 0, \forall x \in C
\end{array}\right.
$$


They first transformed problem (1) into a fixed point problem for the mapping $G=P_{C}(I-\rho A) P_{C}(I-\eta B)$, and then proved strong convergence of the following relaxed extragradient method for solving the problem (1), and the fixed point problem of $S$ :

$$
\left\{\begin{aligned}
y_{n} & =P_{C}\left(x_{n}-\eta B x_{n}\right), n \geq 0, \\
x_{n+1} & =\alpha_{n} u+\beta_{n} x_{n}+\gamma_{n} S P_{C}\left(y_{n}-\rho A y_{n}\right),
\end{aligned}\right.
$$

where $\rho \in(0,2 \alpha), \eta \in(0,2 \beta)$, and $\left\{\alpha_{n}\right\},\left\{\beta_{n}\right\},\left\{\gamma_{n}\right\}$ are sequences in $[0,1]$.

Let $E$ be a real Banach space with the dual $E^{*}$ and $C$ a nonempty closed convex subset of $E$. A self-mapping $f: C \rightarrow C$ is said to be $k$-Lipschitz on $C$ if $k \in \mathbf{R}_{+}=[0,+\infty)$ and $\|f(x)-f(y)\| \leq k\|x-y\|$ for all $x, y \in C$. If $f$ is $k$-Lipschitz with $k<1$, then $f$ is called a $k$-contraction mapping (or a contraction mapping with coefficient $k$ ). A self-mapping $f: C \rightarrow C$ is said to be nonexpansive if it is Lipschitz with $k=1$. Also, recall that a mapping $T$ with domain $D(T)$ and range $R(T)$ in $E$ is called pseudocontractive if the following inequality holds

$$
\|x-y\| \leq\|x-y+r((I-T) x-(I-T) y)\|, \forall x, y \in D(T), r>0,
$$

which is equivalent to the inequality (see [2]) that for each $x, y \in D(T)$ there exists $j(x-y) \in J(x-y)$ such that

$$
\langle T x-T y, j(x-y)\rangle \leq\|x-y\|^{2}
$$

It is known that the class of pseudocontractive mappings is an important and significant generator of nonexpansive mappings [3]. Moreover, interest in pseudocontractive mappings stems mainly from their firm connection with the class of accretive mappings.

Let $A_{1}, A_{2}: C \rightarrow E$ and $M_{1}, M_{2}: C \rightarrow 2^{E}$ be nonlinear mappings. The general system of variational inclusions (GSVI) is to find $\left(x^{*}, y^{*}\right) \in C \times C$ such that

$$
\left\{\begin{array}{l}
0 \in x^{*}-y^{*}+\rho_{1}\left(A_{1} y^{*}+M_{1} x^{*}\right), \\
0 \in y^{*}-x^{*}+\rho_{2}\left(A_{2} x^{*}+M_{2} y^{*}\right),
\end{array}\right.
$$

where $\rho_{1}$ and $\rho_{2}$ are two positive constants.

In 2010, Qin et al. [4] introduced a relaxed extragradient-type method for solving GSVI (4), and proved a strong convergence theorem for the proposed method (for its related results in the literature, see, e.g., [1,5-18]). Furthermore, Aoyama et al. [19] considered the following variational inequality: Find $x^{*} \in C$, such that

$$
\left\langle A x^{*}, j\left(x-x^{*}\right)\right\rangle \geq 0, \quad \forall x \in C .
$$

They proved that the problem (5) is equivalent to a fixed point problem; that is, the element $x^{*} \in C$ is a solution of problem (5) if and only if $x^{*} \in C$ satisfies the following equation:

$$
x^{*}=\Pi_{C}\left(x^{*}-\eta A x^{*}\right),
$$

where $\eta>0$ is a constant and $\Pi_{C}$ is a sunny nonexpansive retraction from $E$ onto $C$. In particular, if $E=H$ a Hilbert space, then $\Pi_{C}$ coincides with the metric projection $P_{C}$ from $H$ onto $C$. Recently, many authors have studied the problem of finding a common element of the set of fixed points of nonlinear mappings and the set of solutions to variational inequalities by iterative methods (see, e.g., [1-3,5,6,8-10,12,14-16,18-24]). 
In particular, Ceng et al. [22] introduced an implicit viscosity approximation method for computing approximate fixed points of a pseudocontractive mapping $T$, and derived strong convergence of the proposed implicit method to a point in $F(T)$, which solves a certain variational inequality.

The purpose of this paper is to solve the GSVI (4) with the hierarchical variational inequality (HVI) constraint, for an infinite family of continuous pseudocontractive mappings $\left\{T_{n}\right\}_{n=1}^{\infty}$ in a uniformly convex and two-uniformly smooth Banach space $E$. By utilizing the equivalence between the GSVI (4) and the fixed point problem, we construct an implicit multiple-viscosity approximation method for solving the GSVI (4) with the HVI constraint, for infinitely many pseudocontractions $\left\{T_{n}\right\}_{n=1}^{\infty}$. Under very mild conditions, we prove the strong convergence of the proposed method to a solution of the GSVI (4) with the HVI constraint, for infinitely many pseudocontractions $\left\{T_{n}\right\}_{n=1}^{\infty}$. Our results improve and extend the corresponding results announced by some others; for example, Yao et al. [13] and Ceng et al. [22].

\section{Preliminaries}

Let $E$ be a real Banach space with dual $E^{*}$. Throughout this paper, we write $x_{n} \rightarrow x$ (respectively, $x_{n} \rightarrow x$ ) to indicate that the sequence $\left\{x_{n}\right\}$ converges weakly (respectively, strongly) to $x$. Let $C$ be a nonempty closed convex subset of $E$. Recall that a mapping $T: C \rightarrow E$ is said to be

(a) accretive if, for each $x, y \in C, \exists j(x-y) \in J(x-y)$ such that $\langle T x-T y, j(x-y)\rangle \geq 0$, where $J$ is the normalized duality mapping;

(b) $\quad \alpha$-strongly accretive if, for each $x, y \in C, \exists j(x-y) \in J(x-y)$ such that $\langle T x-T y, j(x-y)\rangle \geq$ $\alpha\|x-y\|^{2}$ for some $\alpha \in(0,1)$;

(c) $\quad \beta$-inverse-strongly accretive if, for each $x, y \in C, \exists j(x-y) \in J(x-y)$ such that $\langle T x-T y, j(x-y)\rangle \geq$ $\beta\|T x-T y\|^{2}$ for some $\beta>0$.

Let $U=\{x \in E:\|x\|=1\}$ be the unit sphere of $E$. Then $E$ is said to be strictly convex if for any $x, y \in U, x \neq y \Rightarrow\left\|\frac{x+y}{2}\right\|<1$. It is also said to be uniformly convex if for each $\epsilon \in(0,2]$, there exists $\delta>0$ such that for any $x, y \in U,\|x-y\| \geq \epsilon \Rightarrow\left\|\frac{x+y}{2}\right\| \leq 1-\delta$. It is known that a uniformly convex Banach space is reflexive and strictly convex. Also, it is known that if a Banach space $E$ is reflexive, then $E$ is strictly convex if and only if $E^{*}$ is smooth, as well as that $E$ is smooth if and only if $E^{*}$ is strictly convex. A Banach space $E$ is said to have a Gateaux differentiable norm if the limit $\lim _{t \rightarrow 0} \frac{\|x+t y\|-\|x\|}{t}$ exists for each $x, y \in U$ and, in this case, we call $E$ smooth. $E$ is said to have a uniformly Fréchet differentiable norm if the limit is attained uniformly for $x, y \in U$ and, in this case, we call $E$ uniformly smooth. $E$ is also said to have a Fréchet differentiable norm if for each $x \in U$, the limit is attained uniformly for $y \in U$ and, in this case, we call $E$ strongly smooth. The modulus of smoothness of $E$ is defined by

$$
\varrho(\tau)=\sup \left\{\frac{1}{2}(\|x+y\|+\|x-y\|)-1: x, y \in E,\|x\|=1,\|y\|=\tau\right\},
$$

where $\varrho:[0, \infty) \rightarrow[0, \infty)$ is a function. It is known that $E$ is uniformly smooth if and only if $\lim _{\tau \rightarrow 0} \frac{\varrho(\tau)}{\tau}=0$. Let $q$ be a fixed real number with $1<q \leq 2$. A Banach space $E$ is said to be $q$-uniformly smooth if there exists a constant $\kappa>0$, such that $\varrho(\tau) \leq \kappa \tau^{q}$ for all $\tau>0$.

Let $q$ be a real number with $1<q \leq 2$ and let $E$ be a Banach space. Then $E$ is $q$-uniformly smooth if and only if there exists a constant $c>0$ such that

$$
\|x+y\|^{q}+\|x-y\|^{q} \leq 2\left(\|x\|^{q}+\|c y\|^{q}\right), \quad \forall x, y \in E .
$$


The best constant $c$ in the above inequality is called the $q$-uniformly smooth constant of $E$; see [11] for more details. Note that no Banach space is $q$-uniformly smooth for $q>2$; see [25].

For $q>1$, the generalized duality mapping $J_{q}: E \rightarrow 2^{E^{*}}$ is defined by

$$
J_{q}(x)=\left\{\varphi \in E^{*}:\langle x, \varphi\rangle=\|x\|^{q},\|\varphi\|=\|x\|^{q-1}\right\}, \quad \forall x \in E .
$$

In particular, $J=J_{2}$ is called the normalized duality mapping. It is known that $J_{q}(x)=\|x\|^{q-2} J(x), \forall x \in E$. If $E$ is a Hilbert space, then $J=I$ the identity mapping. Recall that

(1) if $E$ is smooth, then $J$ is single-valued and norm-to-weak* continuous on $E$;

(2) if $E$ is uniformly smooth, then $J$ is single-valued and norm-to-norm uniformly continuous on bounded subsets of $E$;

(3) all Hilbert spaces, $L^{p}$ (or $\left.l^{p}\right)$ spaces $(p \geq 2)$ and the Sobolev spaces $W_{m}^{p}(p \geq 2)$, are two-uniformly smooth, while $L^{p}$ (or $\left.l^{p}\right)$ and $W_{m}^{p}$ spaces $(1<p \leq 2)$ are $p$-uniformly smooth;

(4) typical examples of both uniformly convex and uniformly smooth Banach space are $L^{p}$, where $p>1$. More precisely, $L^{p}$ is $\min \{p, 2\}$-uniformly smooth for any $p>1$.

Proposition 1 ([26]). Let $E$ be a smooth and uniformly convex Banach space, and let $r>0$. Then there exists a strictly increasing, continuous and convex function $g:[0,2 r] \rightarrow \mathbf{R}, g(0)=0$ such that $g(\|x-y\|) \leq$ $\|x\|^{2}-2\langle x, j(y)\rangle+\|y\|^{2}, \forall x, y \in B_{r}$, where $B_{r}=\{x \in E:\|x\| \leq r\}$.

Proposition 2 ([27]). If $E$ is a two-uniformly smooth Banach space, then $\|x+y\|^{2} \leq\|x\|^{2}+2\langle y, j(x)\rangle+$ $2\|c y\|^{2}, \forall x, y \in E$, where $c$ is the two-uniformly smooth constant of $E$. In particular, if $E$ is a Hilbert space, then the duality pairing $\langle\cdot, \cdot\rangle$ reduces to the inner product, $j=I$ the identity mapping, and $c=1 / \sqrt{2}$.

Let $D$ be a subset of $C$ and let $\Pi$ be a mapping of $C$ into $D$. Then $\Pi$ is said to be sunny if $\Pi[\Pi(x)+$ $t(x-\Pi(x))]=\Pi(x)$, whenever $\Pi(x)+t(x-\Pi(x)) \in C$ for $x \in C$ and $t \geq 0$. A mapping $\Pi$ of $C$ into itself is called a retraction if $\Pi^{2}=\Pi$. If a mapping $\Pi$ of $C$ into itself is a retraction, then $\Pi(z)=z$ for each $z \in R(\Pi)$, where $R(\Pi)$ is the range of $\Pi$. A subset $D$ of $C$ is called a sunny nonexpansive retract of $C$ if there exists a sunny nonexpansive retraction from $C$ onto $D$.

Proposition 3 ([28]). Let $C$ be a nonempty closed convex subset of a smooth Banach space E, D be a nonempty subset of $C$ and $\Pi$ be a retraction of $C$ onto $D$. Then the following are equivalent:

(i) $\Pi$ is sunny and nonexpansive;

(ii) $\quad\|\Pi(x)-\Pi(y)\|^{2} \leq\langle x-y, j(\Pi(x)-\Pi(y))\rangle, \forall x, y \in C$;

(iii) $\langle x-\Pi(x), j(y-\Pi(x))\rangle \leq 0, \forall x \in C, y \in D$.

Let $C$ be a nonempty closed convex subset of a uniformly convex and uniformly smooth Banach space $E$ and let $T$ be a nonexpansive mapping of $C$ into itself with the fixed point set $F(T) \neq \varnothing$. Then the set $F(T)$ is a sunny nonexpansive retract of $C$; see [29].

Proposition 4 ([30]). Let $C$ be a nonempty closed convex subset of a Banach space $E$ and $T: C \rightarrow C$ be a continuous and strong pseudocontraction mapping. Then, $T$ has a unique fixed point in $C$.

Recall that a possibly multivalued operator $M \subset E \times E$ with domain $D(M)$ and range $R(M)$ in $E$ is accretive if, for each $x_{i} \in D(M)$ and $y_{i} \in M x_{i}(i=1,2)$, there exists $j\left(x_{1}-x_{2}\right) \in J\left(x_{1}-x_{2}\right)$ such that $\left\langle y_{1}-y_{2}, j\left(x_{1}-x_{2}\right)\right\rangle \geq 0$. An accretive operator $M$ is said to satisfy the range condition if $\overline{D(M)} \subset$ $R(I+r M)$ for all $r>0$. An accretive operator $M$ is $m$-accretive if $R(I+r M)=E$ for each $r>0$. If $M$ is 
an accretive operator which satisfies the range condition, then we can define, for each $r>0$, a mapping $J_{r}^{M}: R(I+r M) \rightarrow D(M)$ by $J_{r}^{M}=(I+r M)^{-1}$, which is called the resolvent of $M$. It is well known that $J_{r}^{M}$ is nonexpansive and $F\left(J_{r}^{M}\right)=M^{-1} 0, \forall r>0$; see [31]. Hence, $F\left(J_{r}^{M}\right)=M^{-1} 0=\{x \in D(M): 0 \in M x\}$. If $M^{-1} 0 \neq \varnothing$, then the inclusion $0 \in M x$ is solvable. We below present some lemmas which will be used in the sequel. Some of them are known, and others are not hard to prove.

Lemma 1 ([24]). Let $C$ be a nonempty closed convex subset of a smooth Banach space $E$ and $M: C \rightarrow 2^{E}$ be an m-accretive mapping. Then for any given $r>0$, the inequality holds: $\left\|J_{r}^{M} x-J_{r}^{M} y\right\|^{2} \leq\left\langle x-y, j\left(J_{r}^{M} x-\right.\right.$ $\left.\left.J_{r}^{M} y\right)\right\rangle, \forall x, y \in E$. This means that $J_{r}^{M}: E \rightarrow C$ is nonexpansive.

Lemma 2 ([24]). Let $M: C \rightarrow 2^{E}$ be an m-accretive mapping and $A: C \rightarrow E$ is a mapping. Then $x^{*} \in C$ is a solution of the variational inclusion $0 \in A x+M x$ if and only if $x^{*}=J_{\rho}^{M}\left(x^{*}-\rho A x^{*}\right)$, for all $\rho>0$, that is, $\operatorname{VI}(C, A, M)=F\left(J_{\rho}^{M}(I-\rho A)\right), \forall \rho>0$, where $\operatorname{VI}(C, A, M)$ denotes the set of solutions to this variational inclusion.

Lemma 3 ([24]). Let $M_{1}, M_{2}: C \rightarrow 2^{E}$ be two m-accretive mappings and $A_{1}, A_{2}: C \rightarrow E$ be two mappings. For given $x^{*}, y^{*} \in C,\left(x^{*}, y^{*}\right)$ is a solution of the GSVI (1.4) if and only if $x^{*}$ is a fixed point of the mapping $Q:=J_{\rho_{1}}^{M_{1}}\left(I-\rho_{1} A_{1}\right) J_{\rho_{2}}^{M_{2}}\left(I-\rho_{2} A_{2}\right)$, where $y^{*}=J_{\rho_{2}}^{M_{2}}\left(I-\rho_{2} A_{2}\right) x^{*}$.

Lemma 4 ([32]). Let $C$ be a nonempty closed convex subset of a strictly convex Banach space $E$. Let $T_{1}, T_{2}: C \rightarrow E$ be nonexpansive mappings with $F\left(T_{1}\right) \cap F\left(T_{2}\right) \neq \varnothing$. Define a mapping $S: C \rightarrow E$ by $S x=v T_{1} x+(1-v) T_{2} x$, $\forall x \in C$, where $v$ is a constant in $(0,1)$. Then $S$ is nonexpansive and $F(S)=F\left(T_{1}\right) \cap F\left(T_{2}\right)$.

Lemma 5 ([24]). Let $C$ be a nonempty closed convex subset of a two-uniformly smooth Banach space E. Let the mapping $A: C \rightarrow E$ be $\alpha$-inverse-strongly accretive. Then,

$$
\|(I-\lambda A) x-(I-\lambda A) y\|^{2} \leq\|x-y\|^{2}+2 \lambda\left(c^{2} \lambda-\alpha\right)\|A x-A y\|^{2} .
$$

In particular, if $0 \leq \lambda \leq \frac{\alpha}{c^{2}}$, then $I-\lambda A$ is nonexpansive.

Lemma 6 ([24]). Let $C$ be a nonempty closed convex subset of a two-uniformly smooth Banach space E. Let $M_{1}, M_{2}: C \rightarrow 2^{E}$ be two m-accretive mappings and $A_{i}: C \rightarrow E$ be $\zeta_{i}$-inverse-strongly accretive for $i=1,2$. Let the mapping $Q: C \rightarrow C$ be defined as $Q:=J_{\rho_{1}}^{M_{1}}\left(I-\rho_{1} A_{1}\right) J_{\rho_{2}}^{M_{2}}\left(I-\rho_{2} A_{2}\right)$. If $0 \leq \rho_{i} \leq \frac{\zeta_{i}}{c^{2}}$ for $i=1,2$, then $Q: C \rightarrow C$ is nonexpansive.

Lemma 7 ([33]). Let $J$ be the normalized duality mapping on a real Banach space $E$. Then for all $x, y \in E$, the inequality holds: $\|x+y\|^{2} \leq\|x\|^{2}+2\langle y, j(x+y)\rangle, \forall j(x+y) \in J(x+y)$.

Lemma 8 ([33]). Let $C$ be a nonempty closed convex subset of a uniformly smooth Banach space $E, A: C \rightarrow$ $C$ be a nonexpansive mapping with $F(A) \neq \varnothing$, and $f: C \rightarrow C$ be a fixed contraction mapping. For each $t \in(0,1)$, let $z_{t} \in C$ be the unique fixed point of the contraction $C \ni z \mapsto t f(z)+(1-t) A z$ on $C$, that is, $z_{t}=t f\left(z_{t}\right)+(1-t) A z_{t}$. Then $\left\{z_{t}\right\}$ converges strongly to a point $x^{*} \in F(A)$, which solves the variational inequality: $\left\langle(I-f) x^{*}, j\left(x^{*}-x\right)\right\rangle \leq 0, \forall x \in F(A)$.

Lemma 9 ([33]). Let $\left\{a_{n}\right\}_{n=0}^{\infty}$ be a sequence of nonnegative real numbers satisfying $a_{n+1} \leq\left(1-\lambda_{n}\right) a_{n}+$ $\lambda_{n} \sigma_{n}, \forall n \geq 0$, where $\left\{\lambda_{n}\right\}_{n=0}^{\infty}$ and $\left\{\sigma_{n}\right\}_{n=0}^{\infty}$ are real sequences such that (i) $\left\{\lambda_{n}\right\}_{n=0}^{\infty} \subset(0,1), \sum_{n=0}^{\infty} \lambda_{n}=\infty$, and (ii) either $\lim \sup _{n \rightarrow \infty} \sigma_{n} \leq 0$ or $\sum_{n=0}^{\infty}\left|\lambda_{n} \sigma_{n}\right|<\infty$. Then $\lim _{n \rightarrow \infty} a_{n}=0$. 
Lemma 10 ([34]). Let $C$ be a nonempty closed convex subset of a Banach space E. Let $T_{0}, T_{1}, \ldots$ be a sequence of mappings of $C$ into itself. Suppose that $\sum_{n=1}^{\infty} \sup \left\{\left\|T_{n} x-T_{n-1} x\right\|: x \in C\right\}<\infty$. Then for each $y \in C,\left\{T_{n} y\right\}$ converges strongly to some point of $C$. Moreover, let $T$ be a mapping of $C$ into itself defined by $T y=\lim _{n \rightarrow \infty} T_{n} y$ for all $y \in C$. Then $\lim _{n \rightarrow \infty} \sup \left\{\left\|T x-T_{n} x\right\|: x \in C\right\}=0$.

\section{Main Results}

Now, we are in a position to state and prove our main result.

Theorem 1. Let $C$ be a nonempty closed convex subset of a uniformly convex and two-uniformly smooth Banach space E. Let $M_{1}, M_{2}: C \rightarrow 2^{E}$ be two m-accretive mappings and $A_{i}: C \rightarrow E$ be $\zeta_{i}$-inverse-strongly accretive for $i=1$, 2. Let the mapping $Q: C \rightarrow C$ be defined as $Q:=J_{\rho_{1}}^{M_{1}}\left(I-\rho_{1} A_{1}\right) J_{\rho_{2}}^{M_{2}}\left(I-\rho_{2} A_{2}\right)$, where $0<\rho_{i}<$ $\frac{\zeta_{i}}{c^{2}}, i=1,2$, for $c$ the 2-uniformly smooth constant of $E$. Let $f: C \rightarrow C$ be a fixed contraction mapping with coefficient $k \in[0,1), S: C \rightarrow C$ be a nonexpansive mapping, and $\left\{T_{n}\right\}_{n=1}^{\infty}$ be an infinite family of continuous pseudocontractive mappings of $C$ into itself, such that $\Omega:=\bigcap_{n=1}^{\infty} F\left(T_{n}\right) \cap F(Q) \neq \varnothing$. Let $\left\{\alpha_{n}\right\},\left\{\beta_{n}\right\}$ and $\left\{\gamma_{n}\right\}$ be three real sequences in $(0,1)$ satisfying the following conditions:

(i) $\alpha_{n}+\beta_{n}+\gamma_{n} \leq 1, \forall n \geq 1 ;$
(ii) $\lim _{n \rightarrow \infty} \alpha_{n}=0$ and $\lim _{n \rightarrow \infty} \frac{\beta_{n}}{\alpha_{n}}=0 ;$
(iii) $\lim _{n \rightarrow \infty} \gamma_{n}=1 ;$
(iv) $\sum_{n=1}^{\infty} \alpha_{n}=\infty$

For arbitrary initial value $x_{0} \in C$, compute the sequences $\left\{x_{n}\right\}$ and $\left\{y_{n}\right\}$ such that

$$
\left\{\begin{aligned}
y_{n}= & J_{\rho_{2}}^{M_{2}}\left(x_{n}-\rho_{2} A_{2} x_{n}\right), \\
x_{n}= & \left(1-\alpha_{n}-\beta_{n}-\gamma_{n}\right) x_{n-1}+\alpha_{n} f\left(x_{n-1}\right)+\beta_{n} S x_{n-1} \\
& +\gamma_{n}\left[\mu T_{n} x_{n}+(1-\mu) J_{\rho_{1}}^{M_{1}}\left(y_{n}-\rho_{1} A_{1} y_{n}\right)\right], \quad \forall n \geq 1,
\end{aligned}\right.
$$

where $\mu \in(0,1)$, and $J_{\rho_{i}}^{M_{i}}$ is the resolvent of $M_{i}$ for $i=1,2$. Assume that $\sum_{n=1}^{\infty} \sup _{x \in D}\left\|T_{n+1} x-T_{n} x\right\|<\infty$ for any bounded subset $D$ of $C$, let $T$ be a mapping of $C$ into itself defined by $T x=\lim _{n \rightarrow \infty} T_{n} x$ for all $x \in C$, and suppose that $F(T)=\bigcap_{n=1}^{\infty} F\left(T_{n}\right)$. Then $\left\{x_{n}\right\}$ and $\left\{y_{n}\right\}$ converge strongly to $x^{*}(\in \Omega)$ and $y^{*}$, respectively, where

(a) $\left(x^{*}, y^{*}\right)$ solves the GSVI (4);

(b) $\quad x^{*}$ solves the variational inequality: $\left\langle(I-f) x^{*}, j\left(x^{*}-x\right)\right\rangle \leq 0, \forall x \in \Omega$ (i.e., $x^{*}=\Pi_{\Omega} f\left(x^{*}\right)$ where $\Pi_{\Omega}$ is a sunny nonexpansive retraction from $C$ onto $\Omega$ ).

Proof. Note that the mapping $Q: C \rightarrow C$ is defined as $Q:=J_{\rho_{1}}^{M_{1}}\left(I-\rho_{1} A_{1}\right) J_{\rho_{2}}^{M_{2}}\left(I-\rho_{2} A_{2}\right)$, where $0<\rho_{i}<\frac{\zeta_{i}}{c^{2}}, i=1,2$, for $c$ the two-uniformly smooth constant of $E$. So, by Lemma 6, we know that $Q$ is nonexpansive. It is easy to see that the implicit iterative scheme (7) can be rewritten as

$$
x_{n}=\left(1-\alpha_{n}-\beta_{n}-\gamma_{n}\right) x_{n-1}+\alpha_{n} f\left(x_{n-1}\right)+\beta_{n} S x_{n-1}+\gamma_{n}\left(\mu T_{n} x_{n}+(1-\mu) Q x_{n}\right), \forall n \geq 1 .
$$

Consider the mapping

$$
F_{n} x=\left(1-\alpha_{n}-\beta_{n}-\gamma_{n}\right) x_{n-1}+\alpha_{n} f\left(x_{n-1}\right)+\beta_{n} S x_{n-1}+\gamma_{n}\left(\mu T_{n} x+(1-\mu) Q x\right), \forall x \in C \text {. }
$$


Since $Q: C \rightarrow C$ is a nonexpansive mapping and $T_{n}: C \rightarrow C$ is a continuous pseudocontraction mapping, we deduce that all $x, y \in C$,

$$
\begin{aligned}
\left\langle F_{n} x-F_{n} y, j(x-y)\right\rangle & =\gamma_{n}\left[\mu\left\langle T_{n} x-T_{n} y, j(x-y)\right\rangle+(1-\mu)\langle Q x-Q y, j(x-y)\rangle\right] \\
& \leq \gamma_{n}\left[\mu\|x-y\|^{2}+(1-\mu)\|Q x-Q y\|\|x-y\|\right] \leq \gamma_{n}\|x-y\|^{2} .
\end{aligned}
$$

Hence $F_{n}$ is a continuous and strong pseudocontraction mapping of $C$ into itself (due to $\gamma_{n} \in(0,1)$ ). By Proposition 4, we know that for each $n \geq 1$ there exists a unique element $x_{n} \in C$, satisfying (8).

Next, we divide the rest of the proof into several steps.

Step 1. We claim that $\left\{x_{n}\right\},\left\{y_{n}\right\},\left\{f\left(x_{n}\right)\right\},\left\{S x_{n}\right\},\left\{T_{n} x_{n}\right\}$ and $\left\{Q x_{n}\right\}$ are bounded. Indeed, take an arbitrarily given $p \in \Omega$. Then we have $T_{n} p=p$ and $Q p=p$. Putting $W_{n}:=\mu T_{n}+(1-\mu) Q$, we know that $W_{n}$ is a continuous pseudocontraction mapping of $C$ into itself. Then it follows that $W_{n} p=p$ and

$$
\begin{aligned}
\left\|x_{n}-p\right\|^{2}= & \left\langle x_{n}-p, j\left(x_{n}-p\right)\right\rangle \\
\leq & \left(1-\alpha_{n}-\beta_{n}-\gamma_{n}\right)\left\|x_{n-1}-p\right\|\left\|x_{n}-p\right\|+\alpha_{n}\left\|f\left(x_{n-1}\right)-p\right\|\left\|x_{n}-p\right\| \\
& +\beta_{n}\left\|S x_{n-1}-p\right\|\left\|x_{n}-p\right\|+\gamma_{n}\left\|x_{n}-p\right\|^{2},
\end{aligned}
$$

which hence implies that

$$
\begin{aligned}
\left\|x_{n}-p\right\| \leq & \left(1-\alpha_{n}-\beta_{n}-\gamma_{n}\right)\left\|x_{n-1}-p\right\|+\alpha_{n}\left(\left\|f\left(x_{n-1}\right)-f(p)\right\|+\|f(p)-p\|\right) \\
& +\beta_{n}\left(\left\|S x_{n-1}-S p\right\|+\|S p-p\|\right)+\gamma_{n}\left\|x_{n}-p\right\| \\
\leq & \left(1-(1-k) \alpha_{n}-\gamma_{n}\right)\left\|x_{n-1}-p\right\|+\alpha_{n}\|f(p)-p\|+\beta_{n}\|S p-p\|+\gamma_{n}\left\|x_{n}-p\right\| .
\end{aligned}
$$

Since $\lim _{n \rightarrow \infty} \frac{\beta_{n}}{\alpha_{n}}=0$, we may assume, without loss of generality, that $\beta_{n} \leq \alpha_{n}$ for all $n \geq 1$. This implies that

$$
\begin{aligned}
\left\|x_{n}-p\right\| & \leq\left[1-(1-k) \frac{\alpha_{n}}{1-\gamma_{n}}\right]\left\|x_{n-1}-p\right\|+\frac{\alpha_{n}}{1-\gamma_{n}}\|f(p)-p\|+\frac{\beta_{n}}{1-\gamma_{n}}\|S p-p\| \\
& \leq\left[1-(1-k) \frac{\alpha_{n}}{1-\gamma_{n}}\right]\left\|x_{n-1}-p\right\|+\frac{\alpha_{n}}{1-\gamma_{n}}(\|f(p)-p\|+\|S p-p\|) \\
& \leq \max \left\{\left\|x_{n-1}-p\right\|, \frac{1}{1-k}(\|f(p)-p\|+\|S p-p\|)\right\} .
\end{aligned}
$$

By induction, we derive $\left\|x_{n}-p\right\| \leq \max \left\{\left\|x_{0}-p\right\|, \frac{1}{1-k}(\|f(p)-p\|+\|S p-p\|)\right\}, \forall n \geq 0$. So, $\left\{x_{n}\right\}$ is bounded. Observe that $\left\|f\left(x_{n}\right)\right\| \leq\left\|f\left(x_{n}\right)-f(p)\right\|+\|f(p)\| \leq k\left\|x_{n}-p\right\|+\|f(p)\|$ and $\left\|S x_{n}\right\| \leq$ $\left\|S x_{n}-S p\right\|+\|S p\| \leq\left\|x_{n}-p\right\|+\|S p\|$. This implies that $\left\{f\left(x_{n}\right)\right\}$ and $\left\{S x_{n}\right\}$ are bounded. Similarly, by the nonexpansivity of $Q$ we know that $\left\{Q x_{n}\right\}$ is bounded. Note that $\lim _{n \rightarrow \infty} \gamma_{n}=1$. Hence there exist $n_{0} \geq 1$ and $\varepsilon_{0} \in(0,1)$, such that $\gamma_{n} \geq \varepsilon_{0}$ for all $n \geq n_{0}$. Consequently, we have

$$
\begin{aligned}
\varepsilon_{0}\left\|W_{n} x_{n}\right\| & \leq \gamma_{n}\left\|W_{n} x_{n}\right\|=\left\|x_{n}-\left(1-\alpha_{n}-\beta_{n}-\gamma_{n}\right) x_{n-1}-\alpha_{n} f\left(x_{n-1}\right)-\beta_{n} S x_{n-1}\right\| \\
& \leq\left\|x_{n}\right\|+\left\|x_{n-1}\right\|+\left\|f\left(x_{n-1}\right)\right\|+\left\|S x_{n-1}\right\| .
\end{aligned}
$$

This means that $\left\{W_{n} x_{n}\right\}$ is bounded. Since $W_{n} x_{n}=\mu T_{n} x_{n}+(1-\mu) Q x_{n}$, we get

$$
\mu\left\|T_{n} x_{n}\right\|=\left\|W_{n} x_{n}-(1-\mu) Q x_{n}\right\| \leq\left\|W_{n} x_{n}\right\|+(1-\mu)\left\|Q x_{n}\right\| \leq\left\|W_{n} x_{n}\right\|+\left\|Q x_{n}\right\| .
$$


Hence $\left\{T_{n} x_{n}\right\}$ is bounded. In addition, from Lemma 3 and $p \in \Omega \subset F(Q)$, it follows that $(p, q)$ is a solution of GSVI (4) where $q=J_{\rho_{2}}^{M_{2}}\left(I-\rho_{2} A_{2}\right) p$. So, by Lemmas 1 and 5 we get $\left\|y_{n}\right\| \leq\left\|J_{\rho_{2}}^{M_{2}}\left(I-\rho_{2} A_{2}\right) x_{n}-q\right\|+$ $\|q\| \leq\left\|x_{n}-p\right\|+\|q\|$. That is, $\left\{y_{n}\right\}$ is bounded.

Step 2. We show that $\left\|x_{n}-Q x_{n}\right\| \rightarrow 0$ and $\left\|x_{n}-T x_{n}\right\| \rightarrow 0$ as $n \rightarrow \infty$, where $T: C \rightarrow C$ is defined as $T x=\lim _{n \rightarrow \infty} T_{n} x, \forall x \in C$. For simplicity, put $q=J_{\rho_{2}}^{M_{2}}\left(p-\rho_{2} A_{2} p\right)$ and $z_{n}=J_{\rho_{1}}^{M_{1}}\left(y_{n}-\rho_{1} A_{1} y_{n}\right)$. Then $z_{n}=Q x_{n}, \forall n \geq 1$. From Lemmas 1 and 5 , we have

$$
\begin{aligned}
\left\|y_{n}-q\right\|^{2} & =\left\|J_{\rho_{2}}^{M_{2}}\left(x_{n}-\rho_{2} A_{2} x_{n}\right)-J_{\rho_{2}}^{M_{2}}\left(p-\rho_{2} A_{2} p\right)\right\|^{2} \\
& \leq\left\|x_{n}-p\right\|^{2}-2 \rho_{2}\left(\zeta_{2}-c^{2} \rho_{2}\right)\left\|A_{2} x_{n}-A_{2} p\right\|^{2} .
\end{aligned}
$$

Similarly, we get

$$
\left\|z_{n}-p\right\|^{2} \leq\left\|y_{n}-q\right\|^{2}-2 \rho_{1}\left(\zeta_{1}-c^{2} \rho_{1}\right)\left\|A_{1} y_{n}-A_{1} q\right\|^{2} .
$$

Substituting (10) into (11), we obtain

$$
\left\|z_{n}-p\right\|^{2} \leq\left\|x_{n}-p\right\|^{2}-2 \rho_{2}\left(\zeta_{2}-c^{2} \rho_{2}\right)\left\|A_{2} x_{n}-A_{2} p\right\|^{2}-2 \rho_{1}\left(\zeta_{1}-c^{2} \rho_{1}\right)\left\|A_{1} y_{n}-A_{1} q\right\|^{2} .
$$

From (8) and (12), we conclude

$$
\begin{aligned}
\left\|x_{n}-p\right\|^{2} \leq & \left(1-\alpha_{n}-\beta_{n}-\gamma_{n}\right)\left\|x_{n-1}-p\right\|\left\|x_{n}-p\right\| \\
& +\alpha_{n}\left[\left\langle f\left(x_{n-1}\right)-f(p), j\left(x_{n}-p\right)\right\rangle+\left\langle f(p)-p, j\left(x_{n}-p\right)\right\rangle\right] \\
& +\beta_{n}\left(\left\|S x_{n-1}-S p\right\|+\|S p-p\|\right)\left\|x_{n}-p\right\| \\
& +\gamma_{n}\left(\mu\left\|x_{n}-p\right\|+(1-\mu)\left\|z_{n}-p\right\|\right)\left\|x_{n}-p\right\| \\
\leq & \left(1-\alpha_{n}-\beta_{n}-\gamma_{n}\right)\left\|x_{n-1}-p\right\|\left\|x_{n}-p\right\| \\
& +\alpha_{n}\left[k\left\|x_{n-1}-p\right\|\left\|x_{n}-p\right\|+\left\langle f(p)-p, j\left(x_{n}-p\right)\right\rangle\right]+\beta_{n}\left(\left\|x_{n-1}-p\right\|\right. \\
& +\|S p-p\|)\left\|x_{n}-p\right\|+\gamma_{n} \frac{\left(\mu\left\|x_{n}-p\right\|+(1-\mu)\left\|z_{n}-p\right\|\right)^{2}+\left\|x_{n}-p\right\|^{2}}{2} \\
\leq & {\left[1-(1-k) \alpha_{n}-\gamma_{n}\right] \frac{\left\|x_{n-1}-p\right\|^{2}+\left\|x_{n}-p\right\|^{2}}{2}+\alpha_{n}\left\langle f(p)-p, j\left(x_{n}-p\right)\right\rangle } \\
& +\beta_{n}\|S p-p\|\left\|x_{n}-p\right\|+\gamma_{n}\left\|x_{n}-p\right\|^{2}-\gamma_{n}(1-\mu)\left[\rho_{2}\left(\zeta_{2}-c^{2} \rho_{2}\right)\left\|A_{2} x_{n}-A_{2} p\right\|^{2}\right. \\
& \left.+\rho_{1}\left(\zeta_{1}-c^{2} \rho_{1}\right)\left\|A_{1} y_{n}-A_{1} q\right\|^{2}\right],
\end{aligned}
$$

which together with $\alpha_{n}+\beta_{n}+\gamma_{n} \leq 1$, immediately yields

$$
\begin{gathered}
\gamma_{n}(1-\mu)\left[\rho_{2}\left(\zeta_{2}-c^{2} \rho_{2}\right)\left\|A_{2} x_{n}-A_{2} p\right\|^{2}+\rho_{1}\left(\zeta_{1}-c^{2} \rho_{1}\right)\left\|A_{1} y_{n}-A_{1} q\right\|^{2}\right] \\
\leq\left[1-(1-k) \alpha_{n}-\gamma_{n}\right] \frac{\left\|x_{n-1}-p\right\|^{2}+\left\|x_{n}-p\right\|^{2}}{2}+\alpha_{n}\|f(p)-p\|\left\|x_{n}-p\right\|+\beta_{n}\|S p-p\|\left\|x_{n}-p\right\| .
\end{gathered}
$$

From $\alpha_{n} \rightarrow 0, \frac{\beta_{n}}{\alpha_{n}} \rightarrow 0, \gamma_{n} \rightarrow 1, \rho_{i} \in\left(0, \frac{\zeta_{i}}{c^{2}}\right)$ and the boundedness of $\left\{x_{n}\right\}$, we deduce that

$$
\lim _{n \rightarrow \infty}\left\|A_{2} x_{n}-A_{2} p\right\|=0 \text { and } \lim _{n \rightarrow \infty}\left\|A_{1} y_{n}-A_{1} q\right\|=0 .
$$


Also, utilizing Lemma 1 and Proposition 1, we have

$$
\begin{aligned}
\left\|y_{n}-q\right\|^{2} & \leq\left\langle x_{n}-p, j\left(y_{n}-q\right)\right\rangle+\rho_{2}\left\langle A_{2} p-A_{2} x_{n}, j\left(y_{n}-q\right)\right\rangle \\
& \leq \frac{1}{2}\left[\left\|x_{n}-p\right\|^{2}+\left\|y_{n}-p\right\|^{2}-g_{1}\left(\left\|x_{n}-y_{n}-(p-q)\right\|\right)\right]+\rho_{2}\left\|A_{2} p-A_{2} x_{n}\right\|\left\|y_{n}-q\right\|,
\end{aligned}
$$

which implies that

$$
\left\|y_{n}-q\right\|^{2} \leq\left\|x_{n}-p\right\|^{2}-g_{1}\left(\left\|x_{n}-y_{n}-(p-q)\right\|\right)+2 \rho_{2}\left\|A_{2} p-A_{2} x_{n}\right\|\left\|y_{n}-q\right\| .
$$

Similarly, we get

$$
\left\|z_{n}-p\right\|^{2} \leq\left\|y_{n}-q\right\|^{2}-g_{2}\left(\left\|y_{n}-z_{n}+(p-q)\right\|\right)+2 \rho_{1}\left\|A_{1} q-A_{1} y_{n}\right\|\left\|z_{n}-p\right\| .
$$

Substituting (15) into (16), we get

$$
\begin{aligned}
\left\|z_{n}-p\right\|^{2} \leq & \left\|x_{n}-p\right\|^{2}-g_{1}\left(\left\|x_{n}-y_{n}-(p-q)\right\|\right)-g_{2}\left(\left\|y_{n}-z_{n}+(p-q)\right\|\right) \\
& +2 \rho_{2}\left\|A_{2} p-A_{2} x_{n}\right\|\left\|y_{n}-q\right\|+2 \rho_{1}\left\|A_{1} q-A_{1} y_{n}\right\|\left\|z_{n}-p\right\| .
\end{aligned}
$$

From (13) and (17), we have

$$
\begin{aligned}
\left\|x_{n}-p\right\|^{2} \leq & {\left[1-(1-k) \alpha_{n}-\gamma_{n}\right] \frac{\left\|x_{n-1}-p\right\|^{2}+\left\|x_{n}-p\right\|^{2}}{2}+\alpha_{n}\left\langle f(p)-p, j\left(x_{n}-p\right)\right\rangle } \\
& +\beta_{n}\|S p-p\|\left\|x_{n}-p\right\|+\frac{\gamma_{n}}{2}\left\{\left\|x_{n}-p\right\|^{2}+\mu\left\|x_{n}-p\right\|^{2}+(1-\mu)\left[\left\|x_{n}-p\right\|^{2}\right.\right. \\
& -g_{1}\left(\left\|x_{n}-y_{n}-(p-q)\right\|\right)-g_{2}\left(\left\|y_{n}-z_{n}+(p-q)\right\|\right)+2 \rho_{2}\left\|A_{2} p-A_{2} x_{n}\right\|\left\|y_{n}-q\right\| \\
& \left.\left.+2 \rho_{1}\left\|A_{1} q-A_{1} y_{n}\right\|\left\|z_{n}-p\right\|\right]\right\} \\
= & {\left[1-(1-k) \alpha_{n}-\gamma_{n}\right] \frac{\left\|x_{n-1}-p\right\|^{2}+\left\|x_{n}-p\right\|^{2}}{2}+\alpha_{n}\left\langle f(p)-p, j\left(x_{n}-p\right)\right\rangle } \\
& +\beta_{n}\|S p-p\|\left\|x_{n}-p\right\|+\gamma_{n}\left\|x_{n}-p\right\|^{2}-\frac{\gamma_{n}(1-\mu)}{2}\left[g_{1}\left(\left\|x_{n}-y_{n}-(p-q)\right\|\right)\right. \\
& \left.+g_{2}\left(\left\|y_{n}-z_{n}+(p-q)\right\|\right)\right]+\gamma_{n}(1-\mu)\left(\rho_{2}\left\|A_{2} p-A_{2} x_{n}\right\|\left\|y_{n}-q\right\|\right. \\
& \left.+\rho_{1}\left\|A_{1} q-A_{1} y_{n}\right\|\left\|z_{n}-p\right\|\right),
\end{aligned}
$$

which together with $\alpha_{n}+\beta_{n}+\gamma_{n} \leq 1$, leads to

$$
\begin{aligned}
& \frac{\gamma_{n}(1-\mu)}{2}\left[g_{1}\left(\left\|x_{n}-y_{n}-(p-q)\right\|\right)+g_{2}\left(\left\|y_{n}-z_{n}+(p-q)\right\|\right)\right] \\
& \leq\left[1-(1-k) \alpha_{n}-\gamma_{n}\right] \frac{\left\|x_{n-1}-p\right\|^{2}+\left\|x_{n}-p\right\|^{2}}{2}+\alpha_{n}\|f(p)-p\|\left\|x_{n}-p\right\|+\beta_{n}\|S p-p\|\left\|x_{n}-p\right\| \\
& \quad+\rho_{2}\left\|A_{2} p-A_{2} x_{n}\right\|\left\|y_{n}-q\right\|+\rho_{1}\left\|A_{1} q-A_{1} y_{n}\right\|\left\|z_{n}-p\right\| .
\end{aligned}
$$

Since $\alpha_{n} \rightarrow 0, \frac{\beta_{n}}{\alpha_{n}} \rightarrow 0$ and $\gamma_{n} \rightarrow 1$ as $n \rightarrow \infty$ (from (14)), and by the boundedness of $\left\{y_{n}\right\}$ and $\left\{z_{n}\right\}$, we deduce that $\lim _{n \rightarrow \infty} g_{1}\left(\left\|x_{n}-y_{n}-(p-q)\right\|\right)=0$ and $\lim _{n \rightarrow \infty} g_{2}\left(\left\|y_{n}-z_{n}+(p-q)\right\|\right)=0$. Utilizing the properties of $g_{1}$ and $g_{2}$, we conclude that

$$
\lim _{n \rightarrow \infty}\left\|x_{n}-y_{n}-(p-q)\right\|=0 \text { and } \lim _{n \rightarrow \infty}\left\|y_{n}-z_{n}+(p-q)\right\|=0
$$


From (18), we get $\left\|x_{n}-z_{n}\right\| \leq\left\|x_{n}-y_{n}-(p-q)\right\|+\left\|y_{n}-z_{n}+(p-q)\right\| \rightarrow 0$ as $n \rightarrow \infty$. That is,

$$
\lim _{n \rightarrow \infty}\left\|x_{n}-Q x_{n}\right\|=0
$$

Note that

$$
\gamma_{n}\left\|x_{n}-W_{n} x_{n}\right\| \leq\left(1-\alpha_{n}-\beta_{n}-\gamma_{n}\right)\left\|x_{n-1}-x_{n}\right\|+\alpha_{n}\left\|f\left(x_{n-1}\right)-x_{n}\right\|+\beta_{n}\left\|S x_{n-1}-x_{n}\right\| .
$$

From $\alpha_{n} \rightarrow 0, \frac{\beta_{n}}{\alpha_{n}} \rightarrow 0, \gamma_{n} \rightarrow 1$, and the boundedness of $\left\{x_{n}\right\},\left\{f\left(x_{n}\right)\right\}$, and $\left\{S x_{n}\right\}$, we know that

$$
\lim _{n \rightarrow \infty}\left\|x_{n}-W_{n} x_{n}\right\|=0
$$

Observe that $\mu\left\|T_{n} x_{n}-x_{n}\right\|=\left\|W_{n} x_{n}-x_{n}-(1-\mu)\left(Q x_{n}-x_{n}\right)\right\| \leq\left\|W_{n} x_{n}-x_{n}\right\|+\left\|Q x_{n}-x_{n}\right\|$. In terms of (19) and (20), we obtain

$$
\lim _{n \rightarrow \infty}\left\|x_{n}-T_{n} x_{n}\right\|=0
$$

It is easy to see that $\overline{\operatorname{conv}}\left\{x_{n}\right\}$ is a nonempty bounded closed convex subset of $C$, where $\overline{\operatorname{conv}}\left\{x_{n}\right\}$ is the closed convex hull of the set $\left\{x_{n}\right\}$. By assumption, we get $\sum_{n=1}^{\infty} \sup _{x \in \overline{\operatorname{conv}}\left\{x_{n}\right\}}\left\|T_{n+1} x-T_{n} x\right\|<\infty$. By Lemma 10, we have $\lim _{n \rightarrow \infty} \sup _{x \in \overline{\operatorname{conv}}\left\{x_{n}\right\}}\left\|T_{n} x-T x\right\|=0$. Therefore, by (21), we conclude that

$$
\begin{aligned}
\limsup _{n \rightarrow \infty}\left\|x_{n}-T x_{n}\right\| & \leq \limsup _{n \rightarrow \infty}\left(\left\|x_{n}-T_{n} x_{n}\right\|+\left\|T_{n} x_{n}-T x_{n}\right\|\right) \\
& \leq \limsup _{n \rightarrow \infty}\left\|x_{n}-T_{n} x_{n}\right\|+\limsup _{n \rightarrow \infty} \sup _{x \in \operatorname{conv}\left\{x_{n}\right\}}\left\|T_{n} x-T x\right\|=0 .
\end{aligned}
$$

That is, $\lim _{n \rightarrow \infty}\left\|x_{n}-T x_{n}\right\|=0$.

Step 3. We claim that

$$
\limsup _{n \rightarrow \infty}\left\langle x^{*}-f\left(x^{*}\right), j\left(x^{*}-x_{n}\right)\right\rangle \leq 0, x^{*} \in \Omega,
$$

where $z_{t}$ is the fixed point of the mapping $z \mapsto t f(z)+(1-t)(\mu A+(1-\mu) Q) z$ with $A:=(2 I-T)^{-1}$, $x^{*}=\lim _{t \rightarrow 0^{+}} z_{t}$ and $x^{*}$ solves the VI: $\left\langle(I-f) x^{*}, j\left(x^{*}-x\right)\right\rangle \leq 0, \forall x \in \Omega$.

Indeed, note that the mapping $T: C \rightarrow C$ is defined as $T x:=\lim _{n \rightarrow \infty} T_{n} x$ for all $x \in C$. By assumption, we have that $F(T)=\bigcap_{n=1}^{\infty} F\left(T_{n}\right)$. Let us show that $T: C \rightarrow C$ is pseudocontractive and continuous. As a matter of fact, observe that for all $x, y \in C, \lim _{n \rightarrow \infty}\left\|T_{n} x-T x\right\|=0$ and $\lim _{n \rightarrow \infty}\left\|T_{n} y-T y\right\|=0$. Since each $T_{n}$ is pseudocontractive, we get

$$
\langle T x-T y, j(x-y)\rangle=\lim _{n \rightarrow \infty}\left\langle T_{n} x-T_{n} y, j(x-y)\right\rangle \leq\|x-y\|^{2} .
$$

This means that $T$ is pseudocontractive. In order to show the continuity of $T$ on $C$, we suppose that $u_{n} \rightarrow u$ as $n \rightarrow \infty$ with $u \in C$ and $\left\{u_{n}\right\} \subset C$. Let $D:=\overline{\operatorname{conv}}\left(\left\{u_{n}\right\} \cup\{u\}\right)$, where $\overline{\operatorname{conv}}\left(\left\{u_{n}\right\} \cup\{u\}\right)$ is the closed convex hull of the set $\left\{u_{n}\right\} \cup\{u\}$. Then $D$ is a nonempty bounded closed convex subset of $C$. By assumption, we obtain $\sum_{n=1}^{\infty} \sup _{x \in D}\left\|T_{n+1} x-T_{n} x\right\|<\infty$ for such a subset $D$ of $C$. So, by Lemma 10 we deduce that $\lim _{m \rightarrow \infty} \sup _{x \in D}\left\|T_{m} x-T x\right\|=0$. 
We now observe that, for each given $m, n \geq 1$,

$$
\begin{aligned}
\left\|T u_{n}-T u\right\| & \leq\left\|T u_{n}-T_{m} u_{n}\right\|+\left\|T_{m} u_{n}-T_{m} u\right\|+\left\|T_{m} u-T u\right\| \\
& \leq \sup _{x \in D}\left\|T x-T_{m} x\right\|+\left\|T_{m} u_{n}-T_{m} u\right\|+\left\|T_{m} u-T u\right\| .
\end{aligned}
$$

Since each $T_{m}$ is continuous and $u_{n} \rightarrow u$ as $n \rightarrow \infty$, we have $\lim _{n \rightarrow \infty}\left\|T_{m} u_{n}-T_{m} u\right\|=0$, which together with the last inequality, implies that for each given $m \geq 1$

$$
\begin{aligned}
\limsup _{n \rightarrow \infty}\left\|T u_{n}-T u\right\| & \leq \limsup _{n \rightarrow \infty}\left(\sup _{x \in D}\left\|T x-T_{m} x\right\|+\left\|T_{m} u_{n}-T_{m} u\right\|+\left\|T_{m} u-T u\right\|\right) \\
& \leq \sup _{x \in D}\left\|T x-T_{m} x\right\|+\limsup _{n \rightarrow \infty}\left\|T_{m} u_{n}-T_{m} u\right\|+\left\|T_{m} u-T u\right\| \\
& =\sup _{x \in D}\left\|T x-T_{m} x\right\|+\left\|T_{m} u-T u\right\| .
\end{aligned}
$$

Since $\lim _{m \rightarrow \infty} \sup _{x \in D}\left\|T x-T_{m} x\right\|=0$ and $\lim _{m \rightarrow \infty}\left\|T_{m} u-T u\right\|=0$, we obtain

$$
\limsup _{n \rightarrow \infty}\left\|T u_{n}-T u\right\| \leq \lim _{m \rightarrow \infty} \sup _{x \in D}\left\|T x-T_{m} x\right\|+\lim _{m \rightarrow \infty}\left\|T_{m} u-T u\right\|=0,
$$

that is, $\lim _{n \rightarrow \infty}\left\|T u_{n}-T u\right\|=0$. This means that $T$ is continuous on $C$.

Suppose $A:=(2 I-T)^{-1}$. Then $A$ is nonexpansive and $F(A)=F(T)$ as a consequence of Theorem 6 of [35]. So it follows that $F(A) \cap F(Q)=F(T) \cap F(Q)=\bigcap_{n=1}^{\infty} F\left(T_{n}\right) \cap F(Q)(=: \Omega) \neq \varnothing$. Also, we observe that

$$
\left\|x_{n}-A x_{n}\right\|=\left\|A A^{-1} x_{n}-A x_{n}\right\| \leq\left\|A^{-1} x_{n}-x_{n}\right\|=\left\|(2 I-T) x_{n}-x_{n}\right\|=\left\|x_{n}-T x_{n}\right\| .
$$

Since $\lim _{n \rightarrow \infty}\left\|x_{n}-T x_{n}\right\|=0$, we have $\lim _{n \rightarrow \infty}\left\|x_{n}-A x_{n}\right\|=0$. Meanwhile, from Lemma 4 it is easy to see that $\mu A+(1-\mu) Q$ is nonexpansive and $F(\mu A+(1-\mu) Q)=F(A) \cap F(Q)=\bigcap_{n=1}^{\infty} F\left(T_{n}\right) \cap F(Q)(=$ : $\Omega) \neq \varnothing$. Obviously, the mapping $z \mapsto t f(z)+(1-t)(\mu A+(1-\mu) Q) z$ is a contraction of $C$ into itself for each $t \in(0,1)$. So, $z_{t}$ solves the fixed point equation $z_{t}=t f\left(z_{t}\right)+(1-t)(\mu A+(1-\mu) Q) z_{t}$. Then, we have

$$
z_{t}-x_{n}=(1-t)\left[\mu\left(A z_{t}-x_{n}\right)+(1-\mu)\left(Q z_{t}-x_{n}\right)\right]+t\left(f\left(z_{t}\right)-x_{n}\right)
$$

Thus, from Lemma 7 and (23), we obtain

$$
\begin{aligned}
\left\|z_{t}-x_{n}\right\|^{2} \leq & (1-t)^{2}\left\|\mu\left(A z_{t}-x_{n}\right)+(1-\mu)\left(Q z_{t}-x_{n}\right)\right\|^{2}+2 t\left\langle f\left(z_{t}\right)-x_{n}, j\left(z_{t}-x_{n}\right)\right\rangle \\
\leq & (1-t)^{2}\left\{\mu\left(\left\|z_{t}-x_{n}\right\|^{2}+2\left\|z_{t}-x_{n}\right\|\left\|A x_{n}-x_{n}\right\|+\left\|A x_{n}-x_{n}\right\|^{2}\right)\right. \\
& \left.+(1-\mu)\left(\left\|z_{t}-x_{n}\right\|^{2}+2\left\|z_{t}-x_{n}\right\|\left\|Q x_{n}-x_{n}\right\|+\left\|Q x_{n}-x_{n}\right\|^{2}\right)\right\} \\
& +2 t\left\langle f\left(z_{t}\right)-x_{n}, j\left(z_{t}-x_{n}\right)\right\rangle \\
\leq & (1-t)^{2}\left\{\left\|z_{t}-x_{n}\right\|^{2}+\left\|A x_{n}-x_{n}\right\|\left(2\left\|z_{t}-x_{n}\right\|+\left\|A x_{n}-x_{n}\right\|\right)\right. \\
& \left.+\left\|Q x_{n}-x_{n}\right\|\left(2\left\|z_{t}-x_{n}\right\|+\left\|Q x_{n}-x_{n}\right\|\right)\right\}+2 t\left\langle f\left(z_{t}\right)-x_{n}, j\left(z_{t}-x_{n}\right)\right\rangle,
\end{aligned}
$$

that is,

$$
\begin{aligned}
\left\|z_{t}-x_{n}\right\|^{2} \leq & \left(1+t^{2}\right)\left\|z_{t}-x_{n}\right\|^{2}+\left\|A x_{n}-x_{n}\right\|\left(2\left\|z_{t}-x_{n}\right\|+\left\|A x_{n}-x_{n}\right\|\right) \\
& +\left\|Q x_{n}-x_{n}\right\|\left(2\left\|z_{t}-x_{n}\right\|+\left\|Q x_{n}-x_{n}\right\|\right)+2 t\left\langle f\left(z_{t}\right)-z_{t}, j\left(z_{t}-x_{n}\right)\right\rangle .
\end{aligned}
$$


It follows that

$$
\begin{aligned}
\left\langle z_{t}-f\left(z_{t}\right), j\left(z_{t}-x_{n}\right)\right\rangle \leq & \frac{t}{2}\left\|z_{t}-x_{n}\right\|^{2}+\frac{1}{2 t}\left[\left\|A x_{n}-x_{n}\right\|\left(2\left\|z_{t}-x_{n}\right\|+\left\|A x_{n}-x_{n}\right\|\right)\right. \\
& \left.+\left\|Q x_{n}-x_{n}\right\|\left(2\left\|z_{t}-x_{n}\right\|+\left\|Q x_{n}-x_{n}\right\|\right)\right] .
\end{aligned}
$$

Letting $n \rightarrow \infty$ in (24), from $\left\|x_{n}-A x_{n}\right\| \rightarrow 0$ and $\left\|x_{n}-Q x_{n}\right\| \rightarrow 0$ as $n \rightarrow 0$, we have

$$
\limsup _{n \rightarrow \infty}\left\langle z_{t}-f\left(z_{t}\right), j\left(z_{t}-x_{n}\right)\right\rangle \leq \frac{t}{2} \ell
$$

where $\ell$ is a constant such that $\left\|z_{t}-x_{n}\right\|^{2} \leq \ell$ for all $n \geq 0$ and $t \in(0,1)$. Utilizing Lemma 8 we deduce that $\left\{z_{t}\right\}$ converges strongly to a fixed point $x^{*} \in F(\mu A+(1-\mu) Q)=F(A) \cap F(Q)(=\Omega)$, which solves the variational inequality: $\left\langle(I-f) x^{*}, j\left(x^{*}-x\right)\right\rangle \leq 0, \forall x \in \Omega$. Since $j$ is norm-to-norm uniformly continuous on bounded sets of $E$, as $t \rightarrow 0^{+}$in (25), we get (22).

Step 4. We claim that $x_{n} \rightarrow x^{*}$ and $y_{n} \rightarrow y^{*}$ as $n \rightarrow \infty$, where $\left(x^{*}, y^{*}\right)$ solves the GSVI (4). Indeed, putting $p=x^{*}$ in (13), we obtain

$$
\begin{aligned}
\left\|x_{n}-x^{*}\right\|^{2} \leq & {\left[1-(1-k) \alpha_{n}-\gamma_{n}\right] \frac{\left\|x_{n-1}-x^{*}\right\|^{2}+\left\|x_{n}-x^{*}\right\|^{2}}{2}+\alpha_{n}\left\langle f\left(x^{*}\right)-x^{*}, j\left(x_{n}-x^{*}\right)\right\rangle } \\
& +\beta_{n}\left\|S x^{*}-x^{*}\right\|\left\|x_{n}-x^{*}\right\|+\gamma_{n}\left\|x_{n}-x^{*}\right\|^{2},
\end{aligned}
$$

which hence implies that

$$
\begin{aligned}
\left\|x_{n}-x^{*}\right\|^{2} \leq & \frac{1-(1-k) \alpha_{n}-\gamma_{n}}{1+(1-k) \alpha_{n}-\gamma_{n}}\left\|x_{n-1}-x^{*}\right\|^{2}+\frac{2 \alpha_{n}}{1+(1-k) \alpha_{n}-\gamma_{n}}\left\langle f\left(x^{*}\right)-x^{*}, j\left(x_{n}-x^{*}\right)\right\rangle \\
& +\frac{2 \beta_{n}}{1+(1-k) \alpha_{n}-\gamma_{n}}\left\|S x^{*}-x^{*}\right\|\left\|x_{n}-x^{*}\right\| \\
= & \left(1-\lambda_{n}\right)\left\|x_{n-1}-x^{*}\right\|^{2}+\lambda_{n} \sigma_{n}
\end{aligned}
$$

where $\lambda_{n}=\frac{2(1-k) \alpha_{n}}{1+(1-k) \alpha_{n}-\gamma_{n}}$ and $\sigma_{n}=\frac{1}{1-k}\left\langle f\left(x^{*}\right)-x^{*}, j\left(x_{n}-x^{*}\right)\right\rangle+\frac{\beta_{n}}{(1-k) \alpha_{n}}\left\|S x^{*}-x^{*}\right\|\left\|x_{n}-x^{*}\right\|$.

Now, observe that $(1-k) \alpha_{n}=\frac{2(1-k) \alpha_{n}}{2} \leq \frac{2(1-k) \alpha_{n}}{1-\gamma_{n}+(1-k) \alpha_{n}}=\lambda_{n}$. Since $\sum_{n=1}^{\infty} \alpha_{n}=\infty$, we infer that $\sum_{n=1}^{\infty} \lambda_{n}=\infty$. Note that $\lim _{n \rightarrow \infty} \frac{\beta_{n}}{\alpha_{n}}=0$ and $\lim \sup _{n \rightarrow \infty}\left\langle f\left(x^{*}\right)-x^{*}, j\left(x_{n}-x^{*}\right)\right\rangle \leq 0$, due to (22). Thus, in terms of the boundedness of $\left\{\left\|x_{n}-x^{*}\right\|\right\}$, we have $\lim _{\sup } \operatorname{pos}_{n \rightarrow \infty} \sigma_{n} \leq 0$. Therefore, applying Lemma 9 to (26) implies that $x_{n} \rightarrow x^{*}$ as $n \rightarrow \infty$. Moreover, putting $p=x^{*}$ and $q=y^{*}=J_{\rho_{2}}^{M_{2}}\left(I-\rho_{2} A_{2}\right) x^{*}$ in (18), we have $\lim _{n \rightarrow \infty}\left\|x_{n}-y_{n}-\left(x^{*}-y^{*}\right)\right\|=0$. Also, since $\left\|y_{n}-y^{*}\right\| \leq\left\|x_{n}-y_{n}-\left(x^{*}-y^{*}\right)\right\|+\left\|x^{*}-x_{n}\right\|$, we know that $y_{n} \rightarrow y^{*}$ as $n \rightarrow \infty$. In addition, in terms of Lemma 3 and as $x^{*} \in \Omega \subset F(Q),\left(x^{*}, y^{*}\right)$ solves the GSVI (4).

Author Contributions: All the authors have contributed equally to this paper. All the authors have read and approved the final manuscript.

Funding: This research was partially supported by the Innovation Program of Shanghai Municipal Education Commission (15ZZ068), Ph.D. Program Foundation of Ministry of Education of China (20123127110002) and Program for Outstanding Academic Leaders in Shanghai City (15XD1503100).

Conflicts of Interest: The authors declare no conflict of interest. 


\section{References}

1. Ceng, L.-C.; Wang, C.-Y.; Yao, J.-C. Strong convergence theorems by a relaxed extragradient method for a general system of variational inequalities. Math. Methods Oper. Res. 2008, 67, 375-390. [CrossRef]

2. Yao, Y.-H.; Liou, Y.-C.; Yao, J.-C. Split common fixed point problem for two quasi-pseudocontractive operators and its algorithm construction. Fixed Point Theory Appl. 2015, 2015, 127. [CrossRef]

3. Yao, Y.; Chen, R.; Yao, J.-C. Strong convergence and certain control conditions for modified Mann iteration. Nonlinear Anal. 2008, 68, 1687-1693. [CrossRef]

4. Qin, X.; Chang, S.-S.; Cho, Y.-J.; Kang, S.-M. Approximation of solutions to a system of variational inclusions in Banach spaces. J. Inequal. Appl. 2010, 2010, 916806. [CrossRef]

5. Zegeye, H.; Shahzad, N.; Yao, Y. Minimum-norm solution of variational inequality and fixed point problem in Banach spaces. Optimization 2015, 64, 453-471. [CrossRef]

6. Ceng, L.-C.; Latif, A.; Yao, J.-C. On solutions of a system of variational inequalities and fixed point problems in Banach spaces. Fixed Point Theory Appl. 2013, 2013, 176. [CrossRef]

7. Ceng, L.-C.; Lin, Y.-C.; Wen, C.-F. Iterative methods for triple hierarchical variational inequalities with mixed equilibrium problems, variational inclusions, and variational inequalities constraints. J. Inequal. Appl. 2015, 2015, 16. [CrossRef]

8. Cho, S.-Y.; Qin, X.; Yao, J.-C.; Yao, Y. Viscosity approximation splitting methods for monotone and nonexpansive operators in Hilbert spaces. J. Nonlinear Convex Anal. 2018, 19, 251-264.

9. Yao, Y.; Yao, J.-C.; Liou, Y.-C.; Postolache, M. Iterative algorithms for split common fixed points of demicontractive operators without priori knowledge of operator norms. Carpathian J. Math. 2018, 34, 459-466.

10. Ceng, L.-C.; Latif, A.; Al-Mazrooei, A.-E. Algorithms for common solutions of generalized mixed equilibrium problems and system of variational inclusion problems. J. Nonlinear Sci. Appl. 2016, 9, 3397-3423. [CrossRef]

11. Ceng, L.-C.; Latif, A.; Ansari, Q.-H.; Yao, J.-C. Hybrid extragradient method for hierarchical variational inequalities. Fixed Point Theory Appl. 2014, 2014, 222. [CrossRef]

12. Ceng, L.-C.; Liou, Y.-C.; Wen, C.-F.; Lo, C.-H. Convergence and some control conditions of hybrid steepest-descent methods for systems of variational inequalities and hierarchical variational inequalities. J. Nonlinear Sci. Appl. 2017, 10, 4574-4596. [CrossRef]

13. Yao, Y.-H.; Liou, Y.-C.; Kang, S.-M. Approach to common elements of variational inequality problems and fixed point problems via a relaxed extragradient method. Comput. Math. Appl. 2010, 59, 3472-3480. [CrossRef]

14. Ceng, L.-C.; Latif, A.; Al-Mazrooei, A.-E. Iterative algorithms for systems of generalized equilibrium problems with the constraints of variational inclusion and fixed point problems. Abstr. Appl. Anal. 2014, $2014,540381$. [CrossRef]

15. Ceng, L.-C.; Gupta, H.; Ansari, Q.-H. Implicit and explicit algorithms for a system of nonlinear variational inequalities in Banach spaces. J. Nonlinear Convex Anal. 2015, 16, 965-984.

16. Ceng, L.-C.; Plubtieng, S.; Wong, M.-M.; Yao, J.-C. System of variational inequalities with constraints of mixed equilibria, variational inequalities, and convex minimization and fixed point problems. J. Nonlinear Convex Anal. 2015, 16, 385-421.

17. Ceng, L.-C.; Ansari, Q.-H.; Schaible, S. Hybrid extragradient-like methods for generalized mixed equilibrium problems, systems of generalized equilibrium problems and optimization problems. J. Glob. Optim. 2012, 53, 69-96. [CrossRef]

18. Ceng, L.-C.; Liou, Y.-C.; Wen, C.-F. Systems of variational inequalities with hierarchical variational inequality constraints in Banach spaces. J. Nonlinear Sci. Appl. 2017, 10, 3136-3154. [CrossRef]

19. Aoyama, K.; Iiduka, H.; Takahashi, W. Weak convergence of an iterative sequence for accretive operators in Banach spaces. Fixed Point Theory Appl. 2006, 2006, 35390. [CrossRef]

20. Ceng, L.-C.; Guu, S.-M.; Yao, J.-C. Weak convergence theorem by a modified extragradient method for variational inclusions, variational inequalities and fixed point problems. J. Nonlinear Convex Anal. 2013, 14, 21-31.

21. Yao, Y.-H.; Agarwal, R.-P.; Postolache, M.; Liou, Y.-C. Algorithms with strong convergence for the split common solution of the feasibility problem and fixed point problem. Fixed Point Theory Appl. 2014, 2014, 183. [CrossRef] 
22. Ceng, L.-C.; Petrusel, A.; Wong, M.-M.; Yu, S.-J. Strong convergence of implicit viscosity approximation methods for pseudocontractive mappings in Banach spaces. Optimization 2011, 60, 659-670. [CrossRef]

23. Yao, Y.-H.; Liou, Y.-C.; Yao, J.-C. Iterative algorithms for the split variational inequality and fixed point problems under nonlinear transformations. J. Nonlinear Sci. Appl. 2017, 10, 843-854. [CrossRef]

24. Ceng, L.-C.; Petruşel, A.; Yao, J.-C.; Yao, Y. Hybrid viscosity extragradient method for systems of variational inequalities, fixed points of nonexpansive mappings, zero points of accretive operators in Banach spaces. Fixed Point Theory 2018, 19, 487-502. [CrossRef]

25. Yao, Y.; Qin, X.; Yao, J.-C. Projection methods for firmly type nonexpansive operators. J. Nonlinear Convex Anal. 2018, 19, 407-415.

26. Kamimura, S.; Takahashi, W. Strong convergence of a proximal-type algorithm in a Banach space. SIAM J. Optim. 2002, 13, 938-945. [CrossRef]

27. Xu, H.-K. Inequalities in Banach spaces with applications. Nonlinear Anal. 1991, 16, 1127-1138. [CrossRef]

28. Reich, S. Weak convergence theorems for nonexpansive mappings in Banach spaces. J. Math. Anal. Appl. 1979, 67, 274-276. [CrossRef]

29. Kitahara, S.; Takahashi, W. Image recovery by convex combinations of sunny nonexpansive retractions. Topol. Methods Nonlinear Anal. 1993, 2, 333-342. [CrossRef]

30. Deimling, K. Zeros of accretive operators. Manuscr. Math. 1974, 13, 365-374. [CrossRef]

31. Yao, Y.-H.; Shahzad, N. Strong convergence of a proximal point algorithm with general errors. Optim. Lett. 2012, 6, 621-628. [CrossRef]

32. Bruck, R.-E. Properties of fixed-point sets of nonexpansive mappings in Banach spaces. Trans. Am. Math. Soc. 1973, 179, 251-262. [CrossRef]

33. Xu, H.-K. Viscosity approximation methods for nonexpansive mappings. J. Math. Anal. Appl. 2004, 298, $279-291$. [CrossRef]

34. Aoyama, K.; Kimura, Y.; Takahashi, W.; Toyoda, M. Approximation of common fixed points of a countable family of nonexpansive mappings in a Banach space. Nonlinear Anal. 2007, 67, 2350-2360. [CrossRef]

35. Martin, R.H. Differential equations on closed subsets of Banach space. Trans. Am. Math. Soc. 1973, 179, 399-414. [CrossRef]

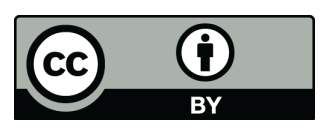

(C) 2018 by the authors. Licensee MDPI, Basel, Switzerland. This article is an open access article distributed under the terms and conditions of the Creative Commons Attribution (CC BY) license (http:/ / creativecommons.org/licenses/by/4.0/). 